algae of the supra-littoral zone of the seashore, and to Janet S. D. Graham's investigations of the influence of mineral nutrition on carbon assimilation. A paper by Prof. J. G. C. Anderson on the Moinian and Dalradin rocks between Glen Roy and the Monadhlieth Mountains is recorded as a contribution to knowledge in a field where there was little previously published information, and Dr. H. I. Drever made further progress in his general study of the origin of the picritic rocks. A list of publications by fellows, scholars and recipients of grants since September 1955 is appended and also a list of awards under the Research Scheme for the year 1956-57.

\section{ORIGIN OF METEOR STREAMS}

$\mathrm{T}$

HE Astronomical Institute of the Czechoslovak Academy of Science has issued a comprehensive monograph by Miroslav Plavec, "On the Origin and Early Stages of the Meteor Streams"*. Plavec discusses the subject in four chapters, the first of which deals with "Cometary Outbursts and the Origin of Meteor Streams". About seven years ago he proved that the mutual gravitational attraction between the particles in a meteor stream is compensated by radiation pressure, in consequence of which there is probably no force holding the particles together. If meteor streams had their origin in the disintegration of comets, there arises the question of how the dispersive forces originate.

A short account of the views of various authors is given, and summed up in four hypotheses : (1) The collision theory, which postulates that, in general, meteor streams originate in collisions of large parental comets with asteroids or meteorites. This view was advocated in 1952 by Whipple and Hamid to explain the Taurid meteors about November 11 ; it was held that Comet Encke had collided with some asteroidal bodies. (2) The disintegration of comets by the tidal actions of the Sun and planets-a view advocated in 1871 by Schiaparelli but no longer considered a very probable explanation. (3) The continuous escape of meteors from the nucleus, which may be a huge cluster of solid bodies of various sizes subjected to internal motions with sufficient speed to exceed the velocity of escape. (4) The ejection hypothesis, which supposes that meteors are emitted from the nucleus by internal forces in the comet.' This view was formulated by Bredichin in 1889 and has comparatively recently been supported by Dubajo and Whipple.

Plaveo explains why he is disposed to prefer this last hypothesis, and deals with the dynamics of the problem in Chapter 2. Special consideration is given to the compact clouds of the Draconids and Leonids, which may be regarded as typical meteor swarms at an early stage of evolution. It is very difficult to explain the formation of these streams by collision because this would involve a much more pronounced dispersion of the swarms than exists. The large dispersion of some other swarms, such as the Perseids and Orionids, could be explained by planetary perturbations of an originally thin stream, as was shown in 1951 by Ahnert and Hamid. It is, however,

- Czechoslovak Academy of Science: Astronomical Institute. Publication No $30:$ On the Origin and Farly Stages of the Meteor Streams, By Miroslav Plavec. Pp. 94. (Prague: Czechoslovak admitted that tidal disintegration as well as ejections may be operating in many comets. The third chapter, "Local Perturbations of the Meteor Streams", explains how planetary perturbations may be responsible for affecting the structure of swarms, and the last chapter shows how the total mass and spatial density of the streams can be determined, and describes the application of the method of computation to the Draconids of 1933. M. Davidson

\section{STRUCTURE AND TAXONOMY OF BULINUS JOUSSEAUMEI}

$\mathrm{N}$ the past the classification of snails of medical 1 and veterinary importance has been based largely on the appearance of their shells, but this system has proved inadequate and classification is now in such confusion that the same snail may be placed in different genera or species by different authorities. It has been recommended that classification should be based on studies of both internal anatomy and shell, but this requires a detailed knowledge of anatomy which is not yet available and which can only be obtained by investigation. During the past three years several important contributions have been made in this direction, but many species have not yet been studied and their identification and relationship to other species are still in doubt. It was this situation which led the British Museum (Natural History), and later the Colonial Medical Research Committee, to establish fellowships in malacology for the study of disease vectors.

Dr. C. A. Wright, at the British Museum (Natural History), has written a paper* which describes a detailed investigation of the internal structure of one of the schistosome vectors in parts of West Africe, and considers its relationships with other species in that area. Some interesting and important results have been obtained. The size of the shell has always been difficult to define and workers have often based their description on the largest specimen or on a range from the smallest to the largest. In this paper it is pointed out that in a sample of snails a normal distribution curve of shell lengths is obtained if those specimens only are considered which have become adult as shown by examination of their reproductive glands. The mean length of adult shells of a species collected from different localities was found to decrease according to their distance from the equator, which is probably to be related to the length of the rainy season.

A careful anatomical and histological examination has been made of the internal organs, particularly the reproductive system, and the findings have been compared with those of other genera and species. In considering the relationship of the snail studied, Dr. Wright reviews the species of the sub-genus Physopsis in West Africa and concludes that the same species is present throughout the area and that B. jousseaumei is one of its forms. On account of its smaller size and more contracted life-cycle he recommends that it should be named Bulinus (Physopsis) globosus jousseanmei. This investigation will simplify the attempt to classify other snails belonging to this sub-genus.

T. H. DAVEY

* Bulletin of the British Museum (Natural History). Zoology. 5 , No. 1: Studies on the Structure and Taxonomy of Bulinus jousseaumei (Dautzenberg). By Dr. C. A. Wright. Pp. 1-28+plates 